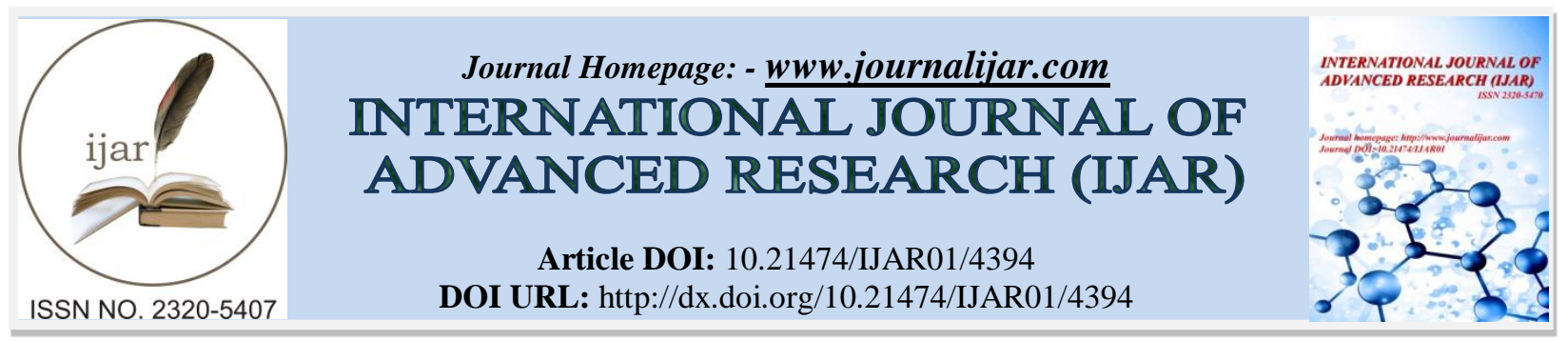

RESEARCH ARTICLE

\title{
PLANNING AND SCHEDULING OF A PROJECT USING MICROSOFT PROJECT (MSP).
}

\author{
Shubham Laddha ${ }^{1}$, Prerna Chanda ${ }^{1}$ and Sneha Khedekar ${ }^{2}$. \\ 1. Student (BE Civil, AISSMS COE, Pune, India). \\ 2. Assistant Professor (AISSMS COE, Pune, India).
}

\section{Manuscript Info}

Manuscript History

Manuscript History

Received: 04 April 2017

Final Accepted: 06 June 2017

Published: June 2017

Key words:-

Microsoft Project, Project Management,

Planning, Scheduling techniques,

Construction Organization.

\section{Abstract}

In spite of all that is known about project management best practices, they are often absent from typical construction projects in India. Our experience is such that weak project management practices continue to be a common place in construction industry, particularly in developing countries. Poorly managed projects cost all stakeholders a huge amount not just financially but also psychologically and emotionally. It has motivated us to carry out the working and functioning of a project using the modern project management tool available in the market; and then comparing it with the traditional software (Excel) which is being use. We carried on an online survey focusing on all the stakeholders related to the project with a view to obtain an idea of various project management practices in construction industry. Notably, $80 \%$ of the total construction industries in India still use traditional software Microsoft Excel for planning, scheduling and controlling of their projects and $86 \%$ felt the need for adapting to new software. We then approached a Pune based construction company in which Excel is still the dominant source of managing the projects. We expressed them our visions and desire to work on one of their projects using Microsoft Project. We carried on the planning \& scheduling of the building using Microsoft Project tool. The results obtained were considerably positive than those using traditional software.

Copy Right, IJAR, 2017,. All rights reserved.

\section{Introduction:-}

"Project is a unique process consisting of a set of coordinated and controlled activities with start and finish dates, undertaken to achieve an objective conforming to specific requirements including constraints of time, cost and resources." (ISO 10006:2003 - Quality Management Systems - Guidelines for Quality Management in Projects 8)

Project management is the discipline of initiating, planning, executing, controlling, and closing the work of a team to achieve specific goals and meet specific success criteria.

In other words, Project Management is the Application of knowledge, skills and Techniques to project activities to meet project requirements. It is a strategic ability to do something successfully for organizations, enabling them to patch the project results to Organizational goals and thus, better compete in their markets. 
It can be also defined as the process and activity of planning, organizing, inspiring, and controlling resources, procedures and protocols to achieve specific goals in scientific or daily problems.

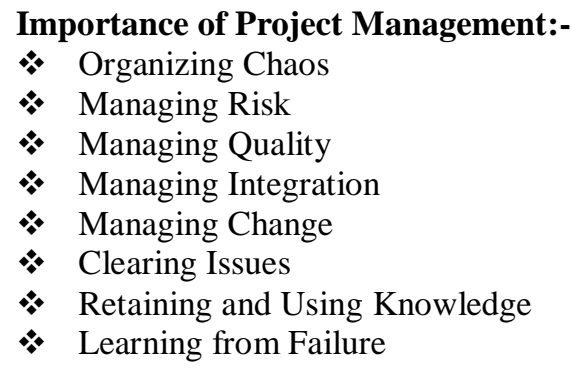

Traditional Approach to Project Management in Construction Sector:-

It has been found that most of the construction industries in India use Excel for planning, monitoring and controlling of a Project. The entire scheduling is done on Excel and the project is tracked against it.

\begin{tabular}{|c|c|c|c|c|}
\hline Sr. No. & Item & Duration & Start Date & Finish Date \\
\hline $\mathbf{A}$ & AVALON & $\mathbf{6 5 7}$ days & $\mathbf{0 1 - 1 0 - 1 2}$ & $\mathbf{2 0 - 0 7 - 1 4}$ \\
\hline $\mathbf{1}$ & Mobilization & $\mathbf{1 3}$ days & $\mathbf{0 1 - 1 0 - 1 2}$ & $\mathbf{1 5 - 1 0 - 1 2}$ \\
\hline $\mathbf{2}$ & Drawings & $\mathbf{0}$ days & $\mathbf{0 1 - 1 0 - 1 2}$ & $\mathbf{0 1 - 1 0 - 1 2}$ \\
\hline & Sub Structure & $\mathbf{9 0}$ days & $\mathbf{1 7 - 1 0 - 1 2}$ & $\mathbf{1 5 - 0 1 - 1 3}$ \\
\hline & Excavation, Backfilling and soling & $\mathbf{6 0}$ days & $\mathbf{1 7 - 1 0 - 1 2}$ & $\mathbf{1 6 - 1 2 - 1 2}$ \\
\hline & Waterproofing & $\mathbf{2 5}$ days & $\mathbf{2 2 - 1 2 - 1 2}$ & $\mathbf{1 6 - 0 1 - 1 3}$ \\
\hline & PCC & $\mathbf{5 0}$ days & $\mathbf{0 7 - 1 1 - 1 2}$ & $\mathbf{2 7 - 1 2 - 1 2}$ \\
\hline $\mathbf{3}$ & RCC of substructure & $\mathbf{6 0}$ days & $\mathbf{1 0 - 1 1 - 1 2}$ & $\mathbf{0 9 - 0 1 - 1 3}$ \\
\hline & Super-structure & $\mathbf{3 9 5}$ days & $\mathbf{0 7 - 1 1 - 1 2}$ & $\mathbf{1 7 - 0 2 - 1 4}$ \\
\hline $\mathbf{4}$ & RCC in superstructure & $\mathbf{2 7 0}$ days & $\mathbf{2 2 - 1 2 - 1 2}$ & $\mathbf{1 8 - 0 9 - 1 3}$ \\
\hline $\mathbf{5}$ & BBM & $\mathbf{1 9 5}$ days & $\mathbf{2 1 - 0 4 - 1 3}$ & $\mathbf{0 2 - 1 1 - 1 3}$ \\
\hline & Plastering & $\mathbf{2 0 2}$ days & $\mathbf{2 1 - 0 5 - 1 3}$ & $\mathbf{1 3 - 0 2 - 1 4}$ \\
\hline & Internal Tar Plastering & 30 days & $21-05-13$ & $02-12-13$ \\
\hline & External Plastering & 60 days & $15-12-13$ & $01-01-14$ \\
\hline $\mathbf{6}$ & Gypsum Plastering & $\mathbf{1 9 5}$ days & $\mathbf{2 1 - 0 5 - 1 3}$ & $13-02-14$ \\
\hline $\mathbf{7}$ & Waterproofing & $\mathbf{2 4 8}$ days & $\mathbf{2 8 - 0 5 - 1 3}$ & $\mathbf{0 2 - 1 2}-13$ \\
\hline
\end{tabular}

Fig 1:- Sample representation of Construction Activities using Microsoft Excel.

\section{About Microsoft Project:-}

Microsoft Project is a project management software product, developed and sold by Microsoft. It is designed to assist a project manager in developing a plan, assigning resources to tasks, tracking progress, managing the budget, and analyzing workloads.

Project creates budgets based on assignment work and resource rates. As resources are assigned to tasks and assignment work estimated, the program calculates the cost, equal to the work times the rate, which rolls up to the task level and then to any summary tasks and finally to the project level. Resource definitions (people, equipment and materials) can be shared between projects using a shared resource pool. Each resource can have its own calendar, which defines what days and shifts a resource is available. Resource rates are used to calculate resource assignment costs which are rolled up and summarized at the resource level. Each resource can be assigned to multiple tasks in multiple plans and each task can be assigned multiple resources, and the application schedules task work based on the resource availability as defined in the resource calendars. All resources can be defined in label without limit. Therefore, it cannot determine how many finished products can be produced with a given amount of raw materials. This makes Microsoft Project unsuitable for solving problems of available materials constrained production. Additional software is necessary to manage a complex facility that produces physical goods. 
The application creates critical path schedules, and critical chain and event chain methodology third-party add-ons also are available. Schedules can be resource leveled, and chains are visualized in a Gantt chart. Additionally, Microsoft Project can recognize different classes of users. These different classes of users can have differing access levels to projects, views, and other data. Custom objects such as calendars, views, tables, filters, and fields are stored in an enterprise global which is shared by all users.

\section{Research Methodology}

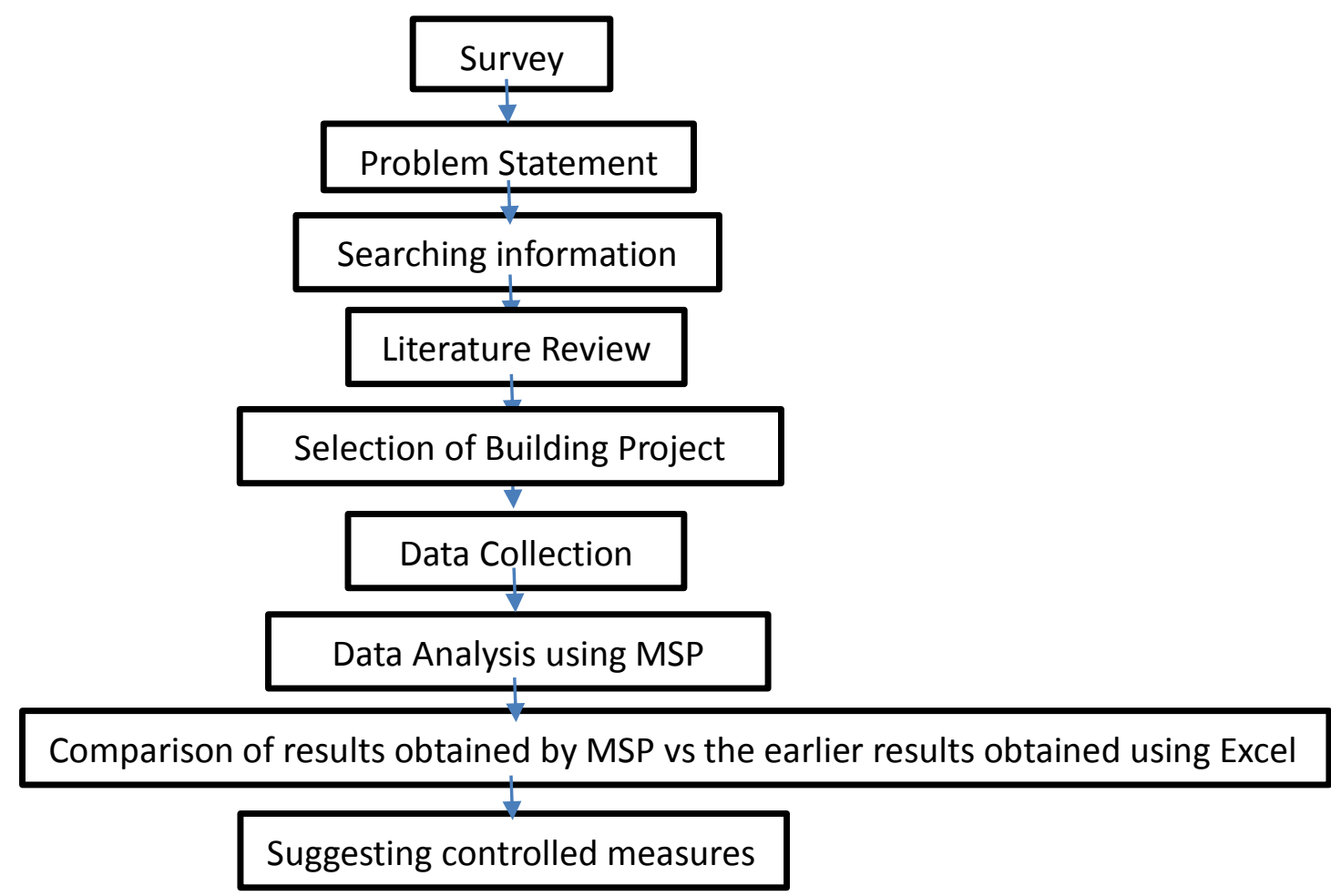

\section{Survey Regarding Project Management Practices:-}

To begin with I started an online survey for understanding and getting a better knowledge of project management trends in private sector. The questions that formed the part of the survey are as follows:

* Name:

* Experience in Years:

* Nature of Your Work:

* Have project management processes been established in your company?

- Do you follow the standard project management process?

* How many times does the scope of project changes during its lifecycle? (Majority of your projects)

* What according to you is most important parameter for today`s builders? (Top Management)

* Is there a proper communication regarding the commencement of project between the top management?

* Is detailed estimate carried out for the entire project?

* Do you measure your projects in Earned Value Management (EVM)/Scope, time, cost?

* How do you calculate activity duration?

- On a scale of 1 to 5, how important is the role of software in construction industry?

( 5 being the highest and 1 being the lowest)

* Which software do you use for planning, monitoring \& scheduling of projects?

* On a scale of 1 to 5, how happy are you with the performance and efficiency of the current software?

( 5 being the highest and 1 being the lowest)

* How important is the need for adaption of new software and tools in construction industry?

The main purpose of the survey was getting a brief idea about the application of project management in construction field and gathering opinions of various personnel in this filed regarding the same. 
The survey was carried out using a google form which was circulated through various mediums like emails \& WhatsApp.

As mentioned in the description any individual related to construction field ranging from engineers, consultant, contractor, architects, managers etc. could fill the survey.

I was expecting 100 responses but the results were much positive on the higher side and we nearly got about 200 responses.

The summary and results below are for the first 200 responses.

Experience in Years: 200 responses

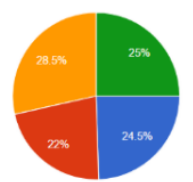

Do you follow the standard project management process? 200 responses

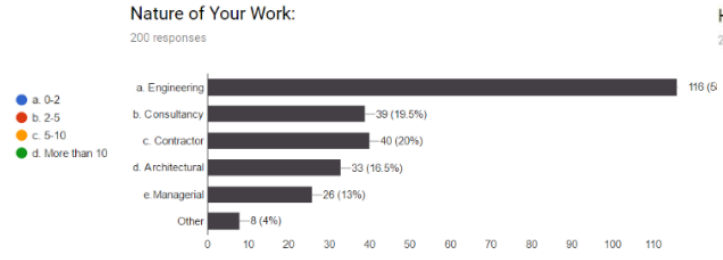

Have project management processes been established in your company? oo ressonses

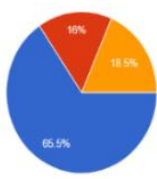

: No How many times does the scope of project changes during its lifecycle? What according to you is most important parameter for today's Builders/Top
(Majority of your projects) majority and not specific]

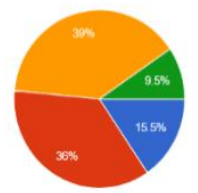

a. Always
D. Oule Scometimes
c. Not Frequenty
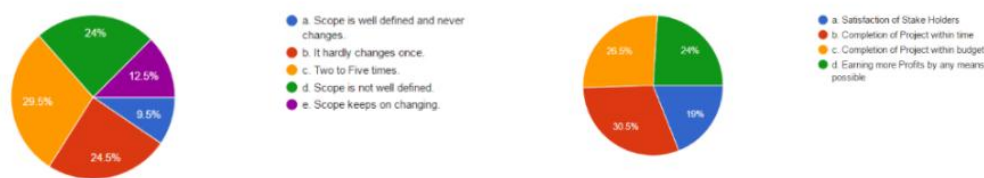

Is there a proper communication regarding the commencement of project Do you measure your projects in Earned Value Management (EVM)/Scope,time,cost?

Is detailed estimate carried out for the entire project? between the on site staff (technical) and the top management?
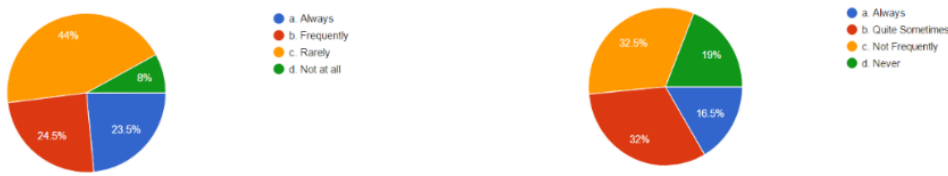
200 responses

How do you calculate activity duration/total project duration?

On a scale of 1 to 5 , how important is the role of software in construction
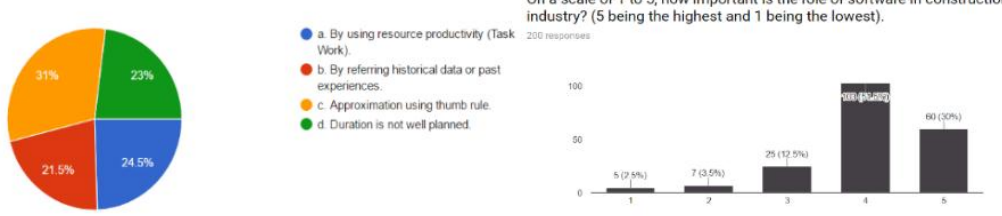

Which software do you use for planning, monitoring \& scheduling of projects? 200 responst

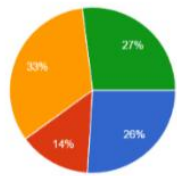

$\because$ a Yes

- C Depends on the trpe at cortract with - A No, thumb rile is used to calculate
apporiximate quantoos

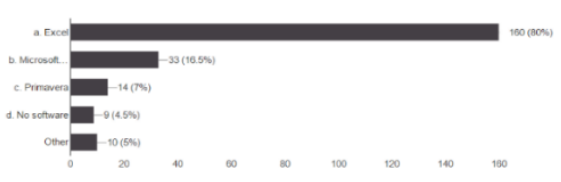


How important is the need for adaption of new software and tools in construction industry?

200 responses
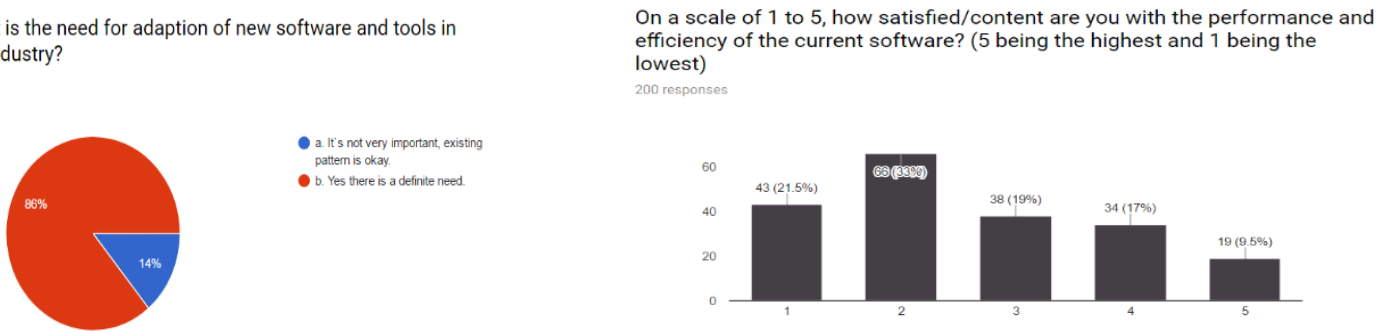

\section{Problem Statement:-}

* As we have seen in the survey, most of the construction industries in India use the traditional software of Microsoft Excel to carry out planning, scheduling and controlling of projects.

* This software not only increases the difficulty of work, it does not give a clear view of completion of work.

* One has to manually enter all durations and dates while double checking that not of these tasks were scheduled over a weekend or holiday.

* Besides many mistakes are made while planning in excel and these mistakes cannot be rectified or spotted easily.

* If one uses Excel to manage his/her project and something goes wrong he/she will have no idea what the residual effects of that change on the entire project are.

* By using Microsoft project, when things change in your schedule you will be able to update your schedule and it will instantly display all affected dates. This will enable the project manager to make better informed decisions as to what corrective action to take and thus have a more effective and up to date project schedule.

* The main purpose of this research is to only indicate the ease of doing of work because of use of better software which are easy to operate, and results obtained are much better than traditional software like Excel.

\section{Research Objective:-}

Basically this thesis will conduct an exploratory study on implementation of Microsoft Project software in every aspect of a project which comprise of Planning and Scheduling stage followed by the Monitoring and Controlling. In this regards, in term of construction management, this dissertation is written for the objectives listed below:

- To study the scheduling techniques to prepare network.

- Planning and scheduling of residential building.

- To prepare a realistic schedule and set baseline.

- To reduce the total duration then the actual executed project's duration (Case Study).

- $\quad$ Ease of work for the Labor.

- To reduce the cost by proper allocation of resources.

\section{Searching Information:-}

Reference Book:-Project management body of knowledge was used to understand the many concepts and technical definitions regarding project management. Few book for the reference of Microsoft project like Project Management Using Microsoft Project 2013: A Training and Reference Guide for Project Managers Using Standard, Professional, Server, Web Application and Project Online" to understand the functioning of software.

Internet:-Plethora of information was gathered from internet with respect to the problems mainly occurred while executing the project in India and also how those problems are tackled with the enormous application of the Microsoft Project.

Study Case:-In order to get the clear view of difference between the traditional way of Project Management and Modern way of managing the project with the help of software called as Microsoft Project the actual example was taken from the Construction organization in Pune, India that uses that uses the Microsoft Excel for the Scheduling and Execution of the project. 
Data Collection:-Data like the Activities Starting Date, Finish Date, Duration of Activities and their Delays, Relationship of Activities and task, Amount of Resources used for the Activities etc. was collected from the Construction Organization of Pune, India to analogize the data and make the data use in the Microsoft Project with the proper changes were made

Data Analysis:-The main activities from the data collected from organization was divided into sub activities for the proper functioning of the project and identification of the Parallel activities, Slacks and crushing of Non-Critical activities was recognized from the given data and appropriate alterations were made to meet the goals of the research.

\section{Scheduling Technique Using Network Models:-}

Using the help of Microsoft Project, it's easy to understand and visualize the flow and network of the project. One can easily see the Critical Path which is the Longest Path of the Project, Parallel Activities, and Slack which is also called as Total Float of the Activity can be visualized, Relation between activities is understood by networking. Owing to this there are fewer obligations while executing and project and right measure can be taken easily.

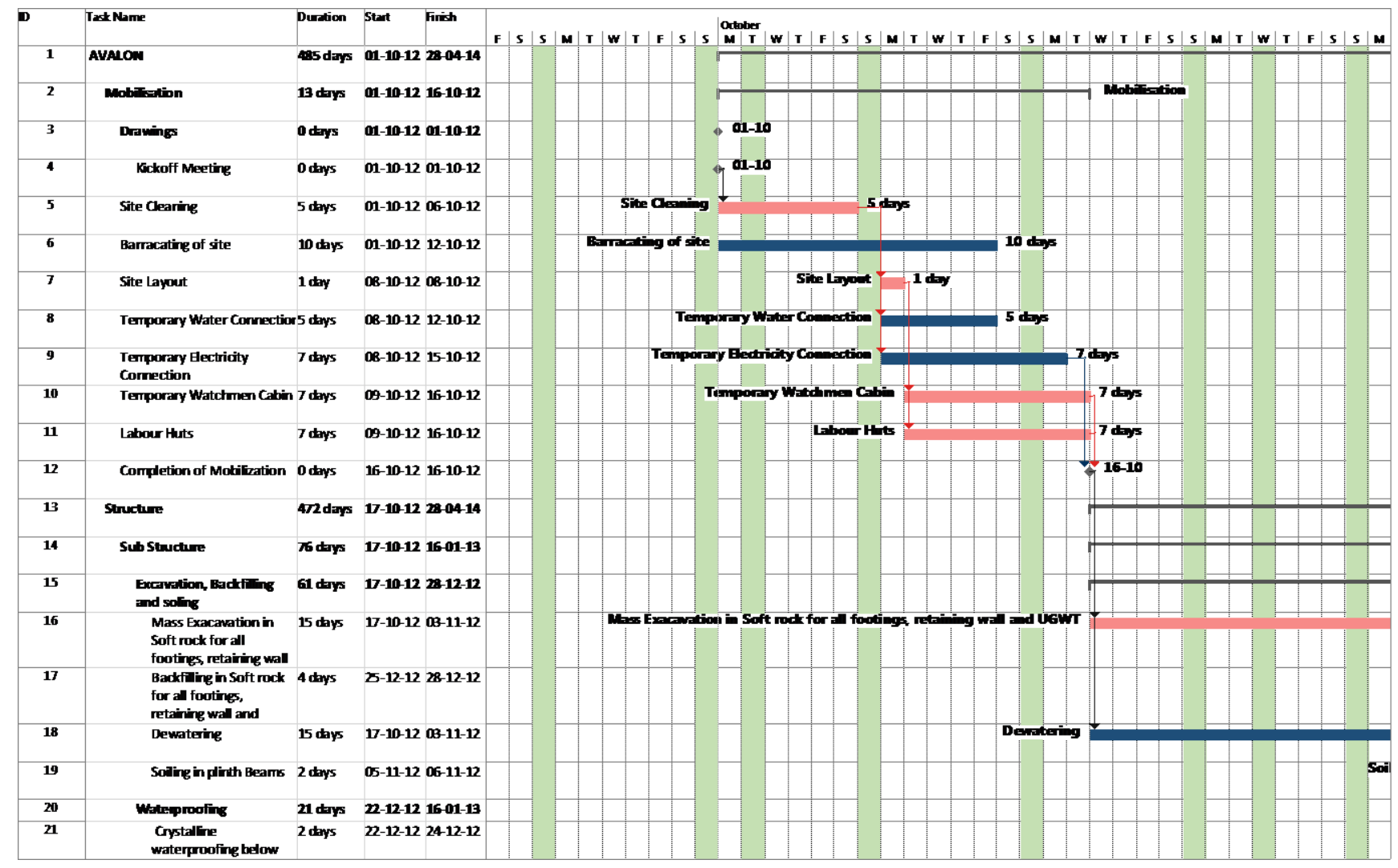

Reduction in the Total Duration of the Project:-

Microsoft Project gives a clear view to understand the project easily. After making proper alteration by using the slacks of parallel activity and crushing the parallel activities the duration of the project has been shown in Graphical form comparing the day required by traditional way and by use of Microsoft Project. The Graph clearly indicates that duration to complete the project by Microsoft Project is less than the Traditional Method obtained from the data of Case Study. 


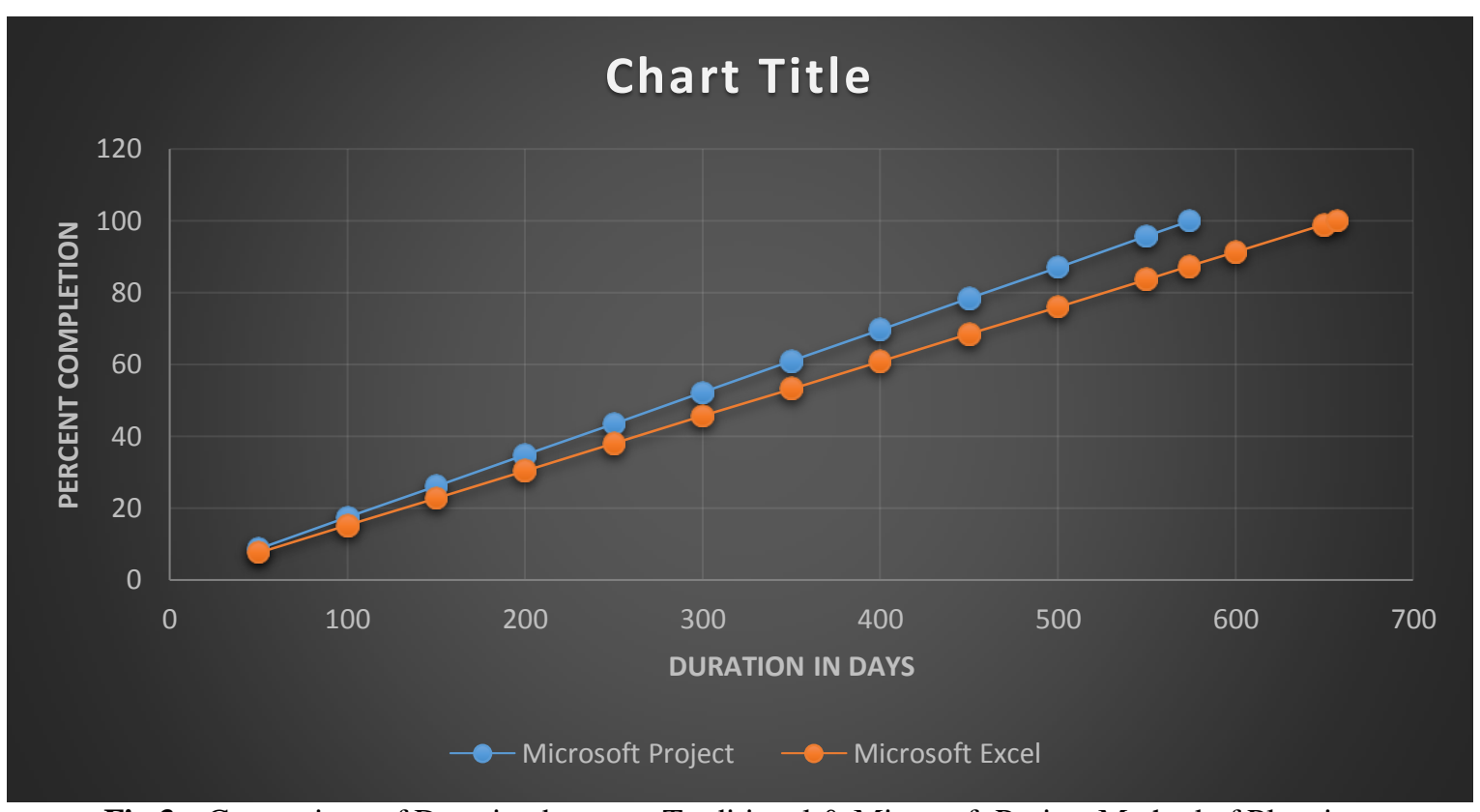

Fig.3:- Comparison of Duration between Traditional \& Microsoft Project Method of Planning.

\section{Provision of Calendar:-}

Calendar enables us to assign proper dates for holidays, ease of labour, procurement of resources and carrying out the proper planning and scheduling.

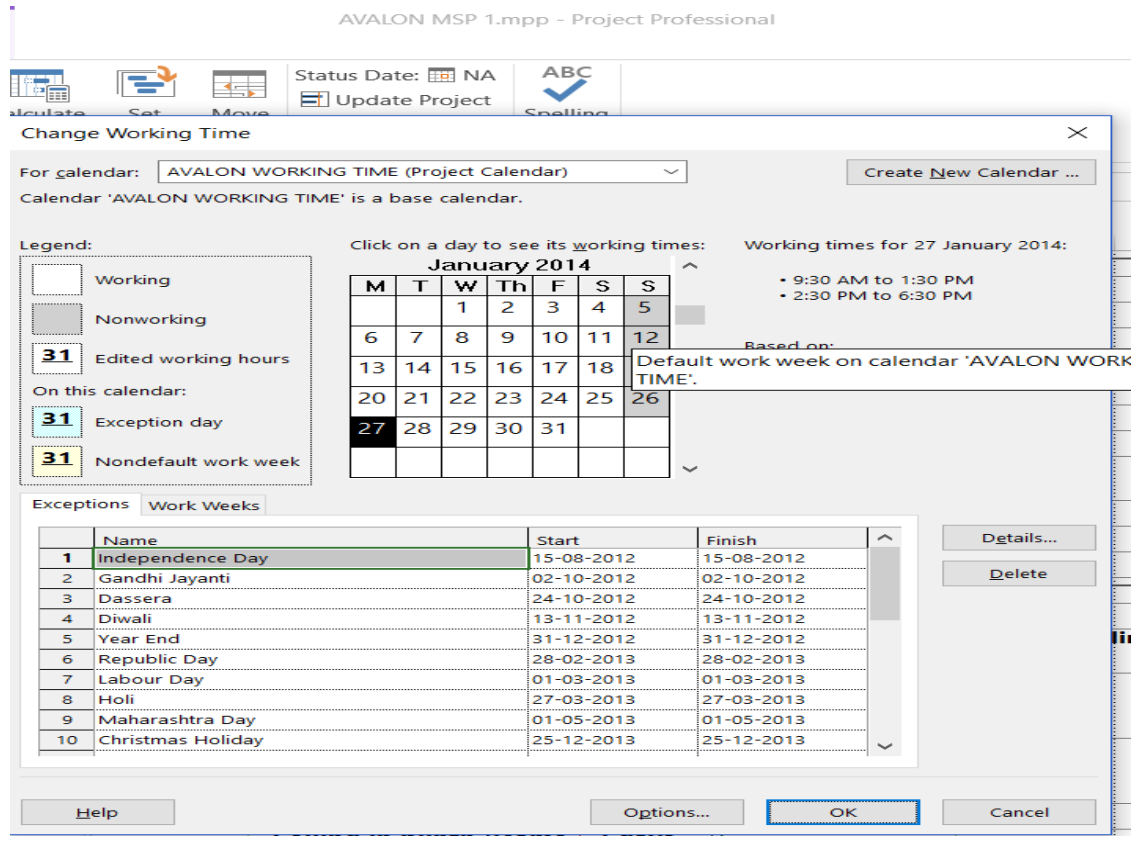

\section{Reduction in the overall Cost of the Project:-}

Proper analysis of the Resources and allocating them without being over allocated is possible using Microsoft Project. By using the fewer Resources where slack time is enough available helps to reduce the cost of the project by $2 \%$ of overall cost of the Traditional way of Management. Besides when the project is completed before time, the overhead charges also reduce contributing to reduction of total cost of project. 


\section{Conclusion:-}

Construction of building using Traditional way proves to be uneconomical and consumes more time with many complexity and enormous error which actual execution of the Project. Traditional way of planning doesn't sub divide the main task which future gets the hurdle of over allocation of resources, improper judgment of resources for particular activities etc. Microsoft Project is the modern tool of Project Management that aid to overcome the obstacles faced owing to traditional way of Planning and Management. It helps for the optimum and effective organization of activities which helps to give the vision to complete the project in planned duration and within the Economy.

\section{References:-}

1. Antonio G. Sanjuana, *. T. (2012). The Application of Project Management Standards and Success Factors to the Development of a Project Management Assessment Tool. Greece: 26th IPMA World Congress.

2. Galloway, P. D. (n.d.). Survey of the Construction Industry Relative to the Use of CPM Scheduling for Construction Projects . ASCE.

3. González1, P., Vicente González, \& Keith Molenaar, F. O. (n.d.). Analysis of Causes of Delay and Time Performance in Construction Projects.

4. Ling1, F. Y., Low2, S. P., Wang3, S., \& Egbelakin4, a. T. (n.d.). Models for Predicting Project Performance in China Using Project Management Practices Adopted by Foreign AEC Firms .

5. Nabil A. Kartam, a. R. (n.d.). INTELLIGENT PLANNING OF CONSTRUCTION PROJECTS .

6. Najuwa Nasira), M. N. (n.d.). Relationship between Time Management in Construction Industry and Project Management Performance. Malaysia.

7. P M Wale1, N. D. ((May. - Jun. 2015). Planning and Scheduling of Project using Microsoft Project (Case Study of a building in India). Pune: IOSR.

8. Shanmuganathan N1, D. G. (n.d.). EFFECTIVE COST AND TIME MANAGEMENT TECHNIQUES IN CONSTRUCTION INDUSTRY. 